\title{
Effect of age on leather and skin traits of slaughter ostriches
}

\author{
S.W.P. Cloete ${ }^{1,2 \#}$, S.J. van Schalkwyk ${ }^{1,3,4}$, L.C. Hoffman ${ }^{1}$ and A. Meyer ${ }^{1,3}$ \\ ${ }^{1}$ Department of Animal Sciences, Private Bag X1, Matieland 7602, South Africa \\ ${ }^{2}$ Elsenburg Agricultural Research Centre, Private Bag X1, Elsenburg 7607, South Africa \\ ${ }^{3}$ Klein Karoo Agricultural Development Centre, PO Box 351, Oudtshoorn 6620, South Africa \\ ${ }^{4}$ Mosstrich, PO Box 2629, Mosselbay 6500, South Africa
}

\begin{abstract}
Little is known about the factors affecting leather and skin traits in ostriches. The effect of age on physical skin traits of slaughter ostriches was consequently investigated. Forty skins representing slaughter ages ranging from five to 14 months were selected to represent means of the respective age groups with regard to skin size and slaughter weight. It was evident that leather thickness increased with age. A similar tendency was observed for tensile strength. The number of nodules $/ \mathrm{dm}^{2}$ declined by 2.8 nodules per month increase in slaughter age. Average nodule diameter increased at a rate of $0.08 \mathrm{~mm}$ per month of age. The number of nodules $/ \mathrm{dm}^{2}$ decreased towards body positions situated nearer to the ventral aspect of the ostrich (upper leg and lower flank). Positions nearer to the centre back had more nodules $/ \mathrm{dm}^{2}$. The nodules on the neck and mid-crown area were smaller in diameter than those situated on the other body positions, with little difference between the upper leg, lower flank and butt positions. Repeatability estimates for the physical skin traits were in the medium to high range. Age thus affects physical leather traits to a lesser extent, apart from leather thickness. It does, however, exert an important influence on the nodule traits that were considered, and needs to be considered in the marketing of ostrich leather.
\end{abstract}

Keywords: Leather thickness, nodule diameter, nodule distribution, slit tear strength, tensile strength

${ }^{\#}$ Corresponding author. E-mail: schalkc@elsenburg.com

\section{Introduction}

Leather contributes markedly to the revenue of commercial ostrich farmers. Cloete et al. (1998) estimated that the contribution of ostrich leather to total income amounted to approximately $70 \%$. This contribution has declined since then, with ostrich meat becoming more popular in European countries after the BSE scare. Leather is however, still estimated to contribute more than $50 \%$ of the total income of ostrich producers, depending on the quality of the product.

Ostrich leather competes in the exotic leather market, and is marketed as a luxury product (Cooper, 2001; Adams \& Revell, 2003). Despite its value little is known about its physical properties and the influence of various factors on it (Sales, 1999). At present skin grading of ostriches depends strongly on physical damage (Meyer et al., 2003b). Industry, however, requires information on aspects such as the tensile strength of leather to determine its suitability for usage in specific products. The occurrence of nodules on the ostrich skin, as determined by the feather follicles, adds to the unique appearance of ostrich leather and is therefore also an important aspect of leather quality. Although the size, shape and distribution of these nodules are alleged to contribute to the marketability of the product, no formal standards are available. The former generalization is the subject of some debate (Sales, 1999). Even though the effect of age on nodule traits has not been substantiated previously in scientific work, Holtzhauzen \& Kotzé (1990) alleged that nodule size is age-dependent. This contention is supported by arguments that tanneries have recently added nodule size as a factor that determines grading in the assessment of skin quality, with a marked influence on the value of the skin. It was contended that this measure was adopted to control an increasing supply of skins with unacceptably small nodules, which resulted from the trend to slaughter ostriches earlier than the traditional 14 months of age to minimize costs and risk (Meyer, 2003). Conventional wisdom has it that slaughter ages earlier than 14 months also result in unfavourable nodule shapes resulting from immature or 'green' feathers.

Against this background this study focused on the effect of age on physical characteristics important for the use of ostrich leather in various leather markets and related industries. The study also reports on the effect of age on nodule parameters measurable on the skin. 


\section{Material and Methods}

A trial was conducted to investigate the effect of slaughter age on ostrich leather traits. For this purpose, 524 ostrich skins from the Klein Karoo Agricultural Development Centre, slaughtered from 1997 to 2000 , were available. The origin and history of the commercial ostrich flock at the Centre, as well as husbandry practices followed, are described adequately in the literature (Bunter, 2002). The skins that were available were screened to find four skins (two from males and two from females) to represent each slaughter age from five months to 14 months. Skins were selected to represent the mean slaughter weight and skin size of the respective age groups as closely as possible. The skin size refers to the size of the skin in the raw stage, as determined immediately after slaughter.

The selected skins were evaluated in the chrome-crusted stage at five different positions on the skin (Figure 1) for the number of nodules in an area of one $\mathrm{dm}^{2}$. The base diameter of 10 individual nodules within each site (chosen according to a predetermined grid) was measured with a Digimatic Caliper. The sizes of individual nodules were then averaged to obtain a single value for each position.

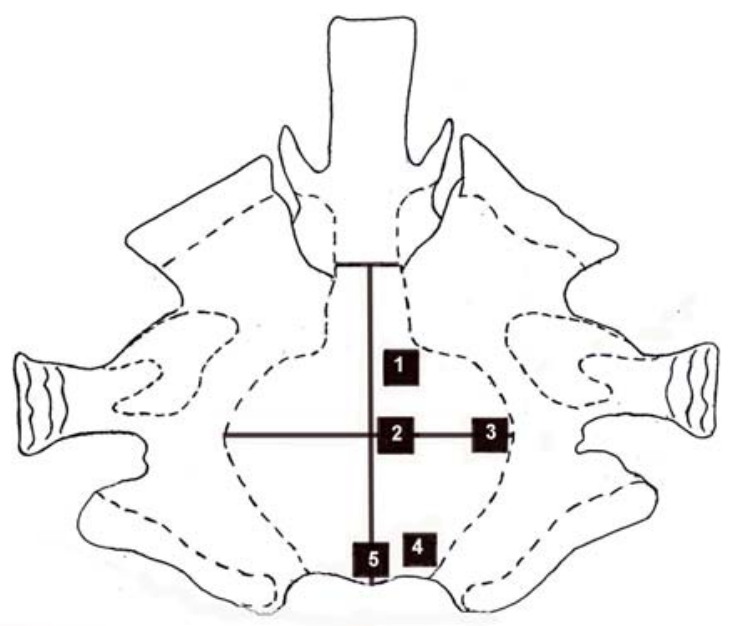

Figure 1 Image of an ostrich skin illustrating the five sample sites for the assessment of nodule traits, viz. sites: 1 - neck; 2 - mid crown area; 3 - upper leg; 4 -lower flank; 5 - butt

An A4-sized leather sample from the butt locality (Site 5 in Figure 1) of each of these skins was obtained and tested at the SA Wool Testing Bureau. The butt region is considered an official sampling position for physical leather traits in lambs (Passman \& Sumner, 1987; Snyman \& Jackson-Moss, 2000). Samples were used to assess for tensile strength, elongation at grain break and slit tear strength on an Instron machine, as described by Snyman \& Jackson-Moss (2000). Tensile strength was defined as the force required for the breaking of a dumbbell-shaped leather sample on the Instron. It was expressed in relation to the diameter at the narrowest part of the dumbbell-shaped piece of leather and the thickness of the sample. Elongation at grain break was determined during the test for tensile strength. It was defined as the percentage stretch of the dumbbell shaped leather sample before it broke. The test for slit tear strength involved a rectangular leather sample with a small slit cut in it. The sample was then pulled apart by a clamp attached to its base and another clamp inserted through the slit. The point at which the slit starts to tear was defined as the slit tear strength. The slit tear strength was expressed in relation to average leather thickness. Leather thickness of each sample was measured in millimetres. Each sample was sub-sampled and assessed in duplicate on samples cut parallel to the spine and perpendicular to the spine, respectively (Cooper et al., 1997; Holst et al., 1997; Snyman \& Jackson-Moss, 2000).

Monthly age group means could be described as longitudinal data. On the assumption that a specific trend would be discernable, a smoothing spline was fitted to the data (Verbyla et al., 1999). The spline consisted of three components, namely: a fixed linear component, random deviations from linearity following a smooth trend, and random deviations from linearity not conforming to a smooth trend. ASREML was used for this purpose (Gilmour et al., 1999). Other fixed effects contained in the model, included gender and orientation of the sample (parallel or perpendicular to the spine - Holst et al., 1997; 
Snyman \& Jackson-Moss, 2000) for the physical leather traits. Sub-samples were taken parallel to or perpendicular to the spine for the assessment of physical leather traits, thus resulting in two measurements from the butt region of the same skin. Nodule number and nodule size were also recorded for five localities on each skin (Figure 1). The same skin was thus sampled repeatedly in both instances. To account for this, the identity of the skin was added as an additional random effect to the models of analysis (Gilmour et al., 1999). This procedure had the advantage that repeatability estimates could be calculated for the physical skin traits, as well as for the number and size of the nodules.

\section{Results}

Group means for slaughter weight and raw skin area inclined linearly with slaughter age $(\mathrm{P}<0.01$; Figure 2). Random deviations from linearity not conforming to a smooth trend were also significant $(\mathrm{P}<$ 0.05), but they were clearly of minor importance when the general pattern in Figure 2 was considered. The overall regressions ( \pm s.e.) for an increase of one month in age amounted to $6.2 \pm 0.4 \mathrm{~kg}$ for slaughter weight, and to $4.2 \pm 0.7$ for skin area $(\mathrm{P}<0.01)$.

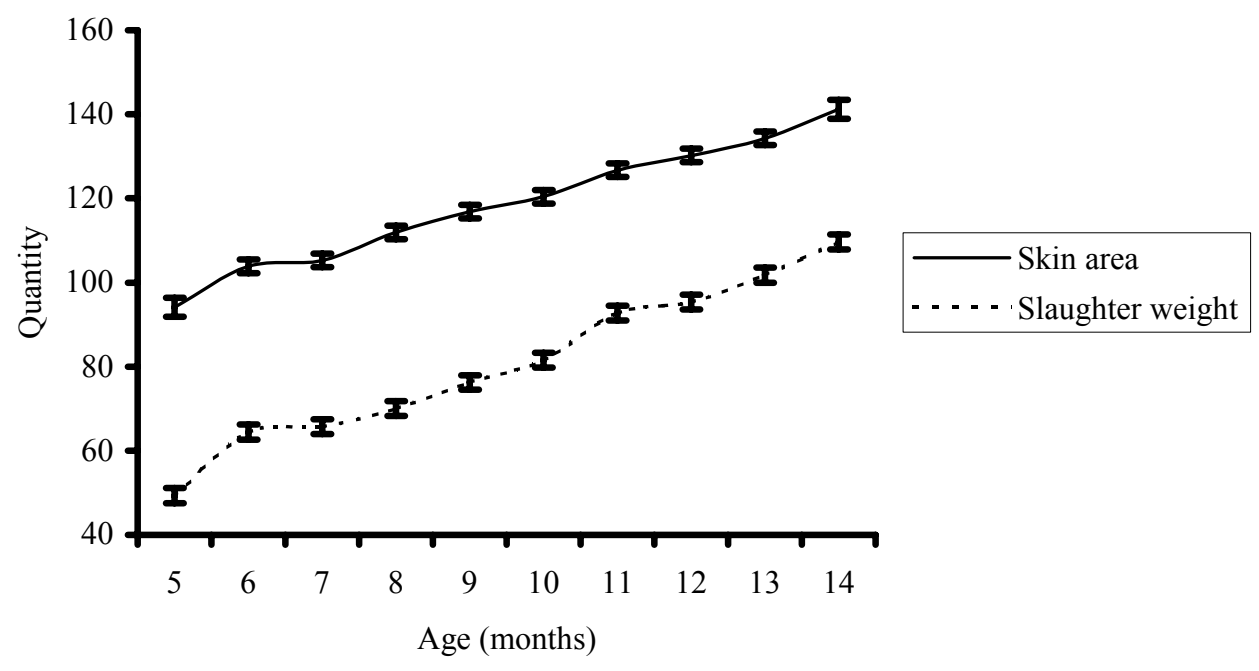

Figure 2 Means depicting the relationship of slaughter weight (in $\mathrm{kg}$ ) and raw skin area (in $\mathrm{dm}^{2}$ ) with slaughter age. Vertical bars about the mean depict standard errors

When physical leather traits were considered, there was a tendency $(\mathrm{P}<0.10)$ for tensile strength to increase by $0.43 \mathrm{~N} / \mathrm{mm}^{2}$ with an increase of one month in slaughter age (Table 1). An increase in skin thickness per month of age at slaughter amounted to $0.05 \mathrm{~mm}$ per month $(\mathrm{P}<0.01)$. No significant trends were obtained for elongation and slit tear strength. Overall, nodule number decreased at a rate of 2.8 nodules $/ \mathrm{dm}^{2}$ for each month increase in slaughter age $(\mathrm{P}<0.01)$. Nodule diameter increased by $0.08 \mathrm{~mm}$ per month as slaughter age increased $(\mathrm{P}<0.01)$.

Another significant fixed effect was that of gender, where males generally had thicker $(\mathrm{P}<0.05)$ skins than females $(0.93 \pm 0.03$ vs. $0.82 \pm 0.03 \mathrm{~mm}$ respectively). The average elongation at grain break of samples cut parallel to the spine was also somewhat lower $(\mathrm{P}<0.05)$ than that of samples cut perpendicular to the spine $(26.9 \pm 0.5 \mathrm{vs}$. $28.3 \pm 0.5 \%$ respectively). These fixed effects did not interact with age at slaughter $(\mathrm{P}>0.10)$.

Sample position had a marked influence upon the number of nodules $/ \mathrm{dm}^{2}$ and average nodule diameter (Table 2). The number of nodules $/ \mathrm{dm}^{2}$ generally decreased $(\mathrm{P}<0.01)$ towards the body positions situated nearer to the ventral aspect of the ostrich (upper leg and lower flank). The positions nearer to the back line had more nodules $/ \mathrm{dm}^{2}$. The nodules on the neck and mid-crown area were smaller $(\mathrm{P}<0.01)$ in diameter than those situated on the other body positions, with little difference between the latter three positions. The repeatability of leather traits was investigated as a by-product of the study (Table 3). These estimates were significant (i.e. more than twice the corresponding standard error), and at least medium in magnitude. 
Table 1 Means ( \pm s.e.) for physical leather properties and nodule parameters, as affected by slaughter age. Regressions of the respective dependent variables on age are also presented. Means are based on four observations, two males and two females per age category

\begin{tabular}{|c|c|c|c|c|c|c|}
\hline \multirow[t]{2}{*}{ Age at slaughter } & \multicolumn{4}{|c|}{ Physical leather properties } & \multicolumn{2}{|c|}{ Nodule traits } \\
\hline & $\begin{array}{l}\text { Strength } \\
\left(\mathrm{N} / \mathrm{mm}^{2}\right)\end{array}$ & $\begin{array}{c}\text { Elongation } \\
(\%)\end{array}$ & $\begin{array}{l}\text { Slit tear } \\
\text { strength } \\
(\mathrm{N} / \mathrm{mm})\end{array}$ & $\begin{array}{l}\text { Thickness } \\
\text { (mm) }\end{array}$ & $\begin{array}{l}\text { Number } \\
\left(\mathrm{n} / \mathrm{dm}^{2}\right)\end{array}$ & $\begin{array}{l}\text { Diameter } \\
(\mathrm{mm})\end{array}$ \\
\hline \multicolumn{7}{|l|}{ Age (months): } \\
\hline 5 & $16.3 \pm 1.3$ & $26.7 \pm 1.0$ & $93.0 \pm 5.4$ & $0.66 \pm 0.05$ & $68.6 \pm 1.7$ & $3.05 \pm 0.07$ \\
\hline 6 & $18.3 \pm 1.2$ & $27.1 \pm 1.0$ & $93.8 \pm 5.0$ & $0.71 \pm 0.05$ & $56.2 \pm 1.5$ & $3.32 \pm 0.06$ \\
\hline 7 & $18.4 \pm 1.1$ & $28.0 \pm 1.0$ & $94.8 \pm 4.7$ & $0.77 \pm 0.04$ & $56.4 \pm 1.5$ & $3.29 \pm 0.06$ \\
\hline 8 & $18.3 \pm 1.0$ & $27.7 \pm 0.9$ & $92.5 \pm 4.5$ & $0.80 \pm 0.04$ & $55.3 \pm 1.5$ & $3.20 \pm 0.06$ \\
\hline 9 & $19.3 \pm 1.0$ & $28.7 \pm 0.9$ & $95.1 \pm 4.4$ & $0.87 \pm 0.04$ & $52.4 \pm 1.5$ & $3.32 \pm 0.06$ \\
\hline 10 & $18.8 \pm 1.0$ & $27.5 \pm 0.9$ & $90.8 \pm 4.4$ & $0.86 \pm 0.04$ & $48.3 \pm 1.5$ & $3.50 \pm 0.06$ \\
\hline 11 & $19.8 \pm 1.0$ & $27.9 \pm 0.9$ & $93.6 \pm 4.5$ & $0.95 \pm 0.04$ & $43.7 \pm 1.5$ & $3.55 \pm 0.06$ \\
\hline 12 & $19.9 \pm 1.1$ & $28.2 \pm 1.0$ & $90.4 \pm 4.7$ & $0.97 \pm 0.04$ & $46.3 \pm 1.5$ & $3.56 \pm 0.06$ \\
\hline 13 & $20.1 \pm 1.2$ & $26.4 \pm 1.0$ & $91.8 \pm 5.0$ & $1.02 \pm 0.05$ & $41.7 \pm 1.5$ & $3.70 \pm 0.06$ \\
\hline 14 & $21.4 \pm 1.3$ & $27.7 \pm 1.0$ & $97.2 \pm 5.4$ & $1.13 \pm 0.05$ & $38.7 \pm 1.7$ & $3.89 \pm 0.07$ \\
\hline Regression $( \pm \mathrm{SE})$ & $0.43 \pm 0.22$ & $0.03 \pm 0.19$ & $0.01 \pm 0.97$ & $0.05 \pm 0.01$ & $-2.79 \pm 0.40$ & $0.08 \pm 0.01$ \\
\hline Significance & $\mathrm{P}<0.10$ & n.s. & n.s. & $* *$ & $* *$ & $* *$ \\
\hline
\end{tabular}

Table 2 Means ( \pm s.e.) for the number of nodules per $\mathrm{dm}^{2}$ (number) and the mean diameter of nodules (mm) measure at five body positions (as depicted in Figure 1) on ostrich skins

\begin{tabular}{|c|c|c|}
\hline \multirow[t]{2}{*}{ Body position } & \multicolumn{2}{|c|}{ Trait } \\
\hline & Nodules $/ \mathrm{dm}^{2}$ & Nodule diameter (mm) \\
\hline $1-$ Neck & $59.2 \pm 1.6^{\mathrm{c}}$ & $2.90 \pm 0.07^{\mathrm{a}}$ \\
\hline $2-$ Mid crown area & $61.2 \pm 1.6^{\mathrm{c}}$ & $3.01 \pm 0.07^{\mathrm{a}}$ \\
\hline 3 - Upper leg & $28.6 \pm 1.6^{\mathrm{a}}$ & $3.64 \pm 0.07^{\mathrm{b}}$ \\
\hline 4 - Lower flank & $42.1 \pm 1.6^{\mathrm{b}}$ & $3.74 \pm 0.07^{b}$ \\
\hline $5-$ Butt & $63.7 \pm 1.6^{\mathrm{c}}$ & $3.76 \pm 0.07^{\mathrm{b}}$ \\
\hline
\end{tabular}

Table 3 Repeatability estimates for physical leather characteristics and nodule traits of ostrich skins

\begin{tabular}{lc}
\hline Trait & Repeatability estimate \pm s.e. \\
\hline Leather quality: & \\
Tensile strength $\left(\mathrm{N} / \mathrm{mm}^{2}\right)$ & $0.48 \pm 0.13$ \\
Elongation $(\%)$ & $0.35 \pm 0.15$ \\
Maximum force $(\mathrm{N} / \mathrm{mm})$ & $0.36 \pm 0.15$ \\
Thickness (mm) & $0.66 \pm 0.10$ \\
& \\
Nodules: & \\
Number $(\mathrm{n})$ & $0.30 \pm 0.09$ \\
Diameter $(\mathrm{mm})$ & $0.40 \pm 0.09$ \\
\hline
\end{tabular}

\section{Discussion}

Few literature sources reporting physical parameters for ostrich leather are available and comparative values from other species were therefore considered. Averages generally accorded with values reported for calf (Cooper et al., 1997) and sheep leather (Snyman \& Jackson-Moss, 2000). The thickness of ostrich leather also corresponded with values of approximately $1 \mathrm{~mm}$ reported for leather derived from lambskin (Holst et al., 1997) and sheepskin (Snyman \& Jackson-Moss, 2000). Angel et al. (1997) reported similar 
mean values for ostrich leather. They found that the average thickness ( \pm s.d.) was $1.0 \pm 0.3 \mathrm{~mm}$, ranging between 0.7 and $1.4 \mathrm{~mm}$, for ostriches slaughtered between 9.1 to 12.7 months of age, on average. Angel et al. (1997) also stated that tensile strength of ostrich skins was very high, regardless of age. The tensile strength of 53 skins in the latter study was above $75 \mathrm{~kg} / \mathrm{cm}^{2}$ (or $7.4 \mathrm{~N} / \mathrm{mm}^{2}$ ). Passman \& Sumner (1987) found that the strength of lambskin increased with age, after correction for leather thickness. This is in partial agreement with results from the present study, where tensile strength tended to increase with age. Skins obtained from older birds were thicker. Angel et al. (1997) correspondingly found that ostrich leather thickness increased linearly with age, with a positive correlation of 0.59 existing between age and leather thickness. In lambskin, leather thickness was found to increase from $0.57 \mathrm{~mm}$ at 10 weeks of age to 0.67 at 30 weeks of age in the flank region (Passman \& Sumner, 1987). Corresponding age differences in the butt region ranged from $0.71 \mathrm{~mm}$ to $0.82 \mathrm{~mm}$ over the same age interval.

The reduction in the number of nodules $/ \mathrm{dm}^{2}$ with an increased age could be explained by the fact that the number of nodules on any one ostrich skin is constant. Conversely, the size of the skin is growth dependent and increases with age. It is therefore to be expected that the nodule density will decrease as the ostrich grows since the same number of nodules is spread over an extended area. As far as nodule size was concerned, Mellet et al. (1996) suggested that the desired nodule size could be obtained as early as 10 months of age, while the ideal nodule shape can only be reached by 14 months. The present study did not attempt to measure the shape of the nodules, but their size continued to increase beyond 10 months of age. In the absence of specific guidelines for minimal requirements for nodule shape and size it is impossible to arrive at conclusive recommendations as far as nodule diameter is concerned. Further research on this topic is indicated to gain a better understanding of the relative importance of nodule size and appearance for skin quality and price determination.

The marked variation in the number of nodules $/ \mathrm{dm}^{2}$ and nodule size is also of interest. In general, body sites with increased numbers of nodules $/ \mathrm{dm}^{2}$ also had smaller nodules. The butt area appears to be an exception to this generalization. This part of the skin combines a high nodule density with a large nodule size. At this stage it cannot be taken for granted that trends in other ostrich populations will be similar to that of the present study, and further research appears to be warranted.

It is important to note that the repeatability estimates for physical leather traits were moderate. A degree of correspondence across localities on a skin cannot be regarded as indicative of selection response in such traits. However, breed differences in the physical leather characteristics of sheep suggest the possibility of genetic influences upon leather quality (Passman \& Dalton, 1982; Passman \& Sumner, 1987; Holst et al., 1997; Snyman \& Jackson-Moss, 2000). Further research in this area is indicated to explore the possibility of altering physical skin and nodule parameters by genetic selection.

The effect of gender on skin thickness was consistent with results reported by Van Schalkwyk et al. (2002). Meyer et al. (2003a) also reported that the average fat-free skin weight of male ostriches was heavier than that of female ostriches. It was found that male broiler chickens had slightly thinner skins, but that the thickness of the dermal layer was higher in males than in females (Christensen et al., 1994). Males also had stronger skins than females. No gender differences in tensile strength or slit tear strength were, however, found in the present study, when corrected for leather thickness.

Holst et al. (1997) reported that the tensile strength of lamb leather samples cut parallel to the spine was higher than that of samples cut perpendicular to the spine. The only significant influence of the orientation of the sample on skin characteristics in the present study was for elongation. In a previous study, Meyer et al. (2003b) found no difference in the relative size of scars left by cut wounds differing in orientation (parallel or perpendicular to the spine). It was argued that the structure of ostrich skin, which comprises of a collagen fibre matrix, contributed to this result.

\section{Conclusions}

Results from the present study clearly suggest that some physical leather traits as well as nodule distribution and nodule size were influenced by age. The importance of age on these parameters may differ according to the intended end use of a specific leather item, i.e. for clothing, footwear, belts etc. (Sales, 1999; Cooper, 2001). In view of the increasing importance of nodule size in the marketplace it was evident that the largest nodule diameters could only be obtained in the oldest age group. Unless it is found to be possible to alter the physical appearance of nodules in another way, e.g. by nutrition or breeding, producers may need to market ostriches at relatively high ages; namely between 12 and 14 months of age. Such a strategy is likely to result in poorer grading, unless skin damage can be prevented in some way. The likelihood of obtaining 
the highest grade for ostrich skins is clearly related to age (Meyer et al., 2002). Heavier groups of slaughter ostriches also sustained more skin damage than low live weight groups of the same age (Meyer et al., 2003a). The reduction in the proportion of first grade skins was attributed to the attainment of puberty in both instances, resulting in an associated increase in aggressive behaviour. Further studies on genetic, environmental and managerial aspects of skin size and skin quality thus seem a prerequisite for the proper understanding of the various interacting mechanisms involved in ostrich skin quality, including physical leather parameters. These aspects need to be understood for the further improvement of ostrich leather quality in the marketplace.

\section{Acknowledgements}

The willingness of the Klein Karoo Co-operation to place ostrich skins for the project at our disposal is acknowledged. We also wish to express our gratitude to the staff of the Klein Karoo Agricultural Development Centre for establishing the resource of ostrich skins.

\section{References}

Adams, J. \& Revell, B.J., 2003. Ostrich farming: - A review and feasibility study of opportunities in the EU. Website address: http://www.mluri.sari.ac.uk/livestocksystems/feasibility/ostrich.htm.

Angel, R., Trevino, L., Mantzel, T., Baltmanis, B., Blue-McLendon, A. \& Pollock, K.D., 1997. Effect of ostrich age on hide quality. American Ostrich, April 1997. pp. 25-26.

Bunter, K.L., 2002. The genetic analysis of reproduction and production traits recorded for farmed ostriches (Struthio camelus). Ph.D. dissertation, University of New England, Armidale, Australia.

Christensen, K.D., Zimmermann, N.G., Wyatt, C.L., Goodman, T.N., Buhr, R.J. \& Twining, P., 1994. Dietary and environmental factors affecting skin strength in broiler chickens. Poult. Sci. 73, 224-235.

Cloete, S.W.P., Van Schalkwyk, S.J. \& Brand, Z., 1998. Ostrich breeding - progress towards a scientifically based strategy. Proc. $2^{\text {nd }}$ Int. Ratite Cong., 21-25 September 1998, Oudtshoorn. pp. 55-62.

Cooper, R.G., 2001. Ostrich (Struthio camelus var. domesticus) skin and leather: A review focused on southern Africa. World's Poult. Sci. J. 57, 157-178.

Cooper, S.M., Gogolewski, R.P. \& Eagleson, J.S., 1997. An evaluation of the quality and physical properties of calf leather following topical application of eprinomectin. N. Z. Vet. J. 45, 202-204.

Gilmour, A.R., Cullis, B.R., Welham, S.J. \& Thompson, R., 1999. ASREML - Reference manuel. NSW Agriculture Biometric Bull. No. 3. NSW Agriculture, Orange Agricultural Institute, Forest Road, Orange 2800, NSW, Australia.

Holst, P.J., Hegarty, R.S., Fogarty, N.M. \& Hopkins, D.L., 1997. Fibre metrology and physical characteristics of lambskins from large Merino and crossbred lambs. Aust. J. Exp. Agric. 37, 509-514.

Holtzhauzen, A. \& Kotzé, M., 1990. The ostrich. C.P. Nel Museum, Oudtshoorn 6620, South Africa.

Mellett, F.D., Fisher, P. \& Böhme, H.M., 1996. Grading of ostrich skins. Proc. Eur. Ostrich Conf., November 1996. Henglo, The Netherlands, European Ostrich Association, Banbury.

Meyer, A., 2003. Behaviour and management of ostriches in relation to skin damage on commercial ostrich farms. M.Sc. thesis, University of the Witwatersrand, Johannesburg, South Africa.

Meyer, A., Cloete, S.W.P. \& Brown, C.R., 2003a. The influence of separate-sex rearing on ostrich behaviour and skin damage. S. Afr. J. Anim. Sci. 33, 95-104.

Meyer, A., Cloete, S.W.P., Brown, C.R. \& Van Schalkwyk, S.J., 2003b. The persistence to slaughter age of scars resulting from damage inflicted to ostrich skins during the grow-out phase. S. Afr. J. Anim. Sci. 33, 32-37.

Meyer, A., Cloete, S.W.P., Van Schalkwyk, S.J. \& Bunter, K.L., 2002. Genetic parameters for live weight and skin traits in ostriches. Proc. World Ostrich Cong. Ed: Horbańchuk, J.O., 26-29 September 2002, Warsaw, Poland. pp. 236-237.

Passman, A. \& Dalton, D.C., 1982. Influence of Romney, Coopworth, and Perendale breeds on lambskin leather quality. N. Z. J. Exp. Agric. 10, 7-13.

Passman, A. \& Sumner, R.M.W., 1987. Effects of breed and age at slaughter on leather produced from export lambs reared on hill country. N. Z. J. Exp. Agric. 15, 309-316.

Sales, J., 1999. Slaughter and products. In: Deeming, D.C. (ed.) The ostrich - Biology, production and health. CABI Publishing, CAB International. Oxon OX10 8 DE, UK. pp. 191-216. 
Snyman, M.A. \& Jackson-Moss, C., 2000. A comparison of the leather produced from skins of ten different South African sheep breeds. Grootfontein Agric. 2(2), 17-21.

Van Schalkwyk, S.J., Cloete, S.W.P., Hoffman, L.C., Brand, T.S., Meyer, A. \& Pfister, A.P., 2002. The effect of dietary energy and protein levels on skin size and physical leather parameters of ostriches. Proc. World Ostrich Cong. Ed: Horbańchuk, J.O., 26-29 September 2002, Warsaw, Poland. pp. 216217.

Verbyla, A.P., Cullis, B.R., Kenward, M.G. \& Welham, S.J., 1999. The analysis of designed experiments and longitudinal data using smoothing splines. J. Royal Stat. Soc. Series C 48, 269-311. 